\title{
Analysis of Output Constancy Checks Using Process Control Techniques in Linear Accelerators
}

\author{
Se An Oh*, Ji Woon Yea* ${ }^{\star}$, Sang Won Kim*, Rena Lee ${ }^{\ddagger}$, Sung Kyu Kim* \\ *Department of Radiation Oncology, Yeungnam University Medical Center, \\ ${ }^{\dagger}$ Department of Radiation Oncology, Yeungnam University College of Medicine, Daegu, \\ ${ }^{\dagger}$ Department of Radiation Oncology, School of Medicine, Ewha Womans University, Seoul, Korea
}

\begin{abstract}
The purpose of this study is to evaluate the results for the quality assurance through a statistical analysis on the output characteristics of linear accelerators belonging to Yeungnam University Medical Center by using the Shewhart-type chart, Exponentially weighted moving average chart (EWMA) chart, and process capability indices $\mathrm{C}_{p}$ and $\mathrm{C}_{\mathrm{pk}}$. To achieve this, we used the output values measured using respective treatment devices (21EX, $21 \mathrm{EX}-\mathrm{S}$, and Novalis Tx) by medical physicists every month from September, 2012 to April, 2014. The output characteristics of treatment devices followed the IAEA TRS-398 guidelines, and the measurements included photon beams of $6 \mathrm{MV}, 10 \mathrm{MV}$, and $15 \mathrm{MV}$ and electron beams of $4 \mathrm{MeV}, 6 \mathrm{MeV}, 9 \mathrm{MeV}, 12 \mathrm{MeV}, 16 \mathrm{MeV}$, and $20 \mathrm{MeV}$. The statistical analysis was done for the output characteristics measured, and was corrected every month. The width of control limit of weighting factors and measurement values were calculated as $\lambda=0.10$ and $L=2.703$, respectively; and the process capability indices $C_{p}$ and $C_{p k}$ were greater than or equal to 1 for all energies of the linear accelerators (21EX, 21EX-S, and Novalis Tx). Measured values of output doses with drastic and minor changes were found through the Shewhart-type chart and EWMA chart, respectively. The process capability indices $\mathrm{Cp}$ and Cpk of the treatment devices in our institution were, respectively, 2.384 and 2.136 for 21EX, 1.917 and 1.682 for 21EX-S, and 2.895 and 2.473 for Novalis Tx, proving that Novalis Tx has the most stable and accurate output characteristics.
\end{abstract}

Key Words: Output characteristics, Linear accelerator, Quality assurance, Process capability, Processability

\section{서 론}

암환자의 방사선치료에서 사용되고 있는 치료기는 대부 분 선형가속기(Medical linear accelerator)를 사용하고 있다. 방사선치료에서는 계획된 선량이 정확하게 전달되는 지 확 인하는 정도관리(Quality Assurance, QA)를 수행하고 있다. 특히, 세기조절방사선치료(Intensity modulated radiotherapy, $\left.\mathrm{IMRT}^{1}\right)^{1}$ 와 같은 복잡한 치료계획에서는 계산된 방사선량이

This work was supported by the Nuclear Safety Research Program through the Korea Radiation Safety Foundation (KORSAF) and the Nuclear Safety and Security Commission (NSSC), Republic of Korea (Grant No. 1305033).

Received 29 April 2014, Revised 1 September 2014, Accepted 4 September 2014

Correspondence: Sung Kyu Kim (skkim3@ynu.ac.kr) Tel: 82-53-620-3373, Fax: 82-53-624-3599

(C) This is an Open-Access article distributed under the terms of the Creative Commons Attribution Non-Commercial License (http://creativecommons.org/licenses/by-nc/3.0) which permits unrestricted non-commercial use, distribution, and reproduction in any medium, provided the original work is properly cited.
암부위에 정확히 전달되는 지 확인이 이루어진 후에 치료 가 수행되어야 한다.

이러한 방사선치료에서의 정도관리는 차료기에서 출력 된 방사선량이 암환자에게 까지 전달되는 데는 치료기의 출력선량, 계산된 선량이 암환자에게 전달되는 전달선량으 로 이루어진다. 치료과정에서 암환자에게 처방되는 방사선 처방선량이 정확하게 암부위에 전달되는 것이 중요하다. 정확한 처방선량을 수행하기 위해서 첫째는, 선형가속기에 서 출력되는 출력선량이 정확해야 한다. 정확한 출력을 얻 기 위해서 IAEA TRS-398 ${ }^{2}$ 과 AAPM TG 50 $0^{3}$ 에서는 출력선 량에 대한 가이드라인을 권고하고 있다. 둘째는, 암부위에 전달되는 방사선 계획선량의 정확성에 있다. 암부위에 주변 중요 장기에 대한 계획선량의 평가를 위하여 ICRU Report $83^{4}$ 에서는 세기조절방사선치료에 대한 가이드라인을 제시 하고 있다. 셋째는, 계산된 방사선처방량이 암부위에 정확 하게 전달되어야 한다. 여기서 언급된 출력선량, 계획선량, 전달선량이 정확하게 이루어져야 방사선치료가 정확하게 
Se An Oh, et al : Analysis of Output Constancy Checks Using Process Control Techniques in Linear Accelerators

수행되는 것이다.

선형가속기의 출력특성 조사는 환자 치료에 앞서 확인 하고 검증해야할 가장 중요한 사항이다. 대부분의 병원에 서 매월 출력 특성을 교정하고 확인하여 환자에게 적용하 고 있지만 출력 특성에 대한 통계학적 분석을 통한 안정성 평가는 잘 이루어지지 않고 있는 실정이다. 앞으로 선형가 속기의 출력특성에 대한 안전성 평가를 위하여 통계적 분 석이 시행되어져야 할 것으로 생각하며 우선 본 병원의 선 형가속기에 대한 출력 특성에 대한 통계적 분석을 시도하 였다.

이 논문에서는 본원이 보유하고 있는 선형가속기의 출 력 특성에 대한 통계학적 분석 평가 ${ }^{5-12}$ 를 통하여 출력선량 의 정확성과 안정성에 대한 특성을 평가하였다.

\section{재료 및 방법}

선형가속기의 품질보증을 위하여 통계학적 분석 자료에 사용된 치료기는 본원에 설치된 선형가속기의 출력 특성을 사용하였다. 사용 된 선형가속기는 2001년에 설치된 Varian Clinic 21EX, 2005년에 설치된 21EX-S와 2012년에 설치된 Novalis Tx (Varian Medical System, USA and BrainLAB, Feldkirchen, Germany)였으며, 치료기들의 출력 특성은 IAEA TRS-398의 가이드 라인을 따랐으며, 측정 에너지는 광자선 $6 \mathrm{MV}, 10 \mathrm{MV}, 15 \mathrm{MV}$ 와 전자선 $4 \mathrm{MeV}, 6 \mathrm{MeV}, 9 \mathrm{MeV}, 12$ $\mathrm{MeV}, 16 \mathrm{MeV}, 20 \mathrm{MeV}$ 였다.

출력 특성을 측정하기 위한 계측기는 Dose-1 electrometer (IBA, GmBH, Scanditronix Wellhofer, Germany)였으며, 이 때 사용한 이온전리함은 광자선 측정 시에는 $0.65 \mathrm{cc}$ 부피를 가지는 farmer type의 FC-65G (IBA, GmBH, Scanditronix Wellhofer, Germany) 였으며, 전자선 측정 시에는 $0.40 \mathrm{cc}$ 의 부피를 가지는 parallel plate type의 PPC-40 (IBA, GmBH, Scanditronix Wellhofer, Germany)을 사용하였다. 측정 시 그 날의 기압과 phantom의 물 온도를 보정하였다. 측정에 사 용한 물팬텀(WP34; IBA, GmBH, Schwarzenbruck, Germany) 의 크기는 $30 \times 30 \times 30 \mathrm{~cm}^{3}$ 였다.

본 연구의 통계처리는 Microsoft Excel 2010 (Microsoft Corporation, Red-mond, WA, USA)을 사용하여 직접 계산하 였으며, 본원의 의학물리사에 의하여 IAEA TRS-398의 가 이드라인을 따라서 2012년 9월부터 2014년 4월까지 매월 측정된 각각 치료기들의 출력측정값을 사용하였다.

측정 기준은 광자선에서는 SSD (source-to-skin distance) $100 \mathrm{~cm}$ 에서 치료면적은 $10 \times 10 \mathrm{~cm}^{2}$ 였으며, 물 표면에서 10 $\mathrm{cm}$ 깊이에서 측정하였다. 전자선에서는 SSD $100 \mathrm{~cm}$ 에서 전자선 cone $10 \times 10 \mathrm{~cm}^{2}$ 를 사용하여 에너지에 따라 유효깊 이에서 측정하였다.

모든 에너지에 대한 출력의 오차 한계는 $\pm 3 \%$ 로 하였다. 본 병원이 보유하고 있는 출력 특성 측정 가이드라인을 따 랐으며, 모든 에너지에서 출력 특성의 한계치는 $1.0 \mathrm{~Gy} / \mathrm{MU}$ $\pm 1.0 \%$ 로 하였으며, 이 범위를 벗어나면 재교정을 시도하여 한계치 범위 내에 있게 하였다.

\section{Shewhart-type control chart}

출력값의 상한값과 하한값의 한계는 shewhart-type control chart $(X \text { chart })^{4}$ 를 따랐다.

Shewhart-type control chart는 upper control limit (UCL)과 center line (CL)과 lower control limit (LCL)로 이루어져 있 다. 출력특성 자료는 시간의 변화에 따라 변하는 시간 변수 함수이다.

$\mathrm{CL}$ 은 평균값 $(\mathrm{X})$ 이며, $\mathrm{UCL}$ 과 $\mathrm{LCL}$ 은 평균값에서 \pm 3 의 표 준편차로 하였다. 소그룹은 선형가속기 Varian Clinic 21EX, $21 \mathrm{EXe}$ 와 Novalix $\mathrm{Tx}$ 의 3 대를 기준으로 각각의 선형가속기 측정값을 하나의 소그룹으로 나누었다.

$$
\begin{aligned}
& U C L=\bar{X}+3 \frac{\overline{M R}}{d_{2} \sqrt{n}} \\
& C L=\bar{X} \\
& L C L=\bar{X}-3 \frac{\overline{M R}}{d_{2} \sqrt{n}}
\end{aligned}
$$

여기서 $\mathrm{d}_{2}$ 는 소그룹의 크기에 의존하는 정확도 상수이다. 일반적으로 소그룹의 크기가 1 일 때, $\mathrm{d}_{2}=1.128$ 이다. MR은 두 측정된 연속값의 차의 절대치이며, $\mathrm{MR}_{\mathrm{i}}=\left|\mathrm{X}_{\mathrm{i}}-\mathrm{X}_{\mathrm{i}-1}\right|$ 이다.

$\overline{M R}$ 은 계산된 $\mathrm{MR}$ 의 평균값이다.

선형가속기 Varian Clinic 21EX의 $6 \mathrm{MV}, 10 \mathrm{MV}, 6 \mathrm{MeV}$, $9 \mathrm{MeV}$ 에 대한 shewhart-type control chart는 Fig. 1와 같으 며, 모든 에너지에 대한 shewhart-type control chart는 다음 과 같다(Table 1).

\section{Exponentially weighted moving average (EWMA) chart}

shewhart-type control chart는 측정 과정에서 측정값의 변 화가 클 때의 측정값을 찾아낼 때 사용되며, $\mathrm{EWMA}^{13)}$ 는 측 정과정에서 측정값의 변화가 점진적인 이동이 있을 때의 
a

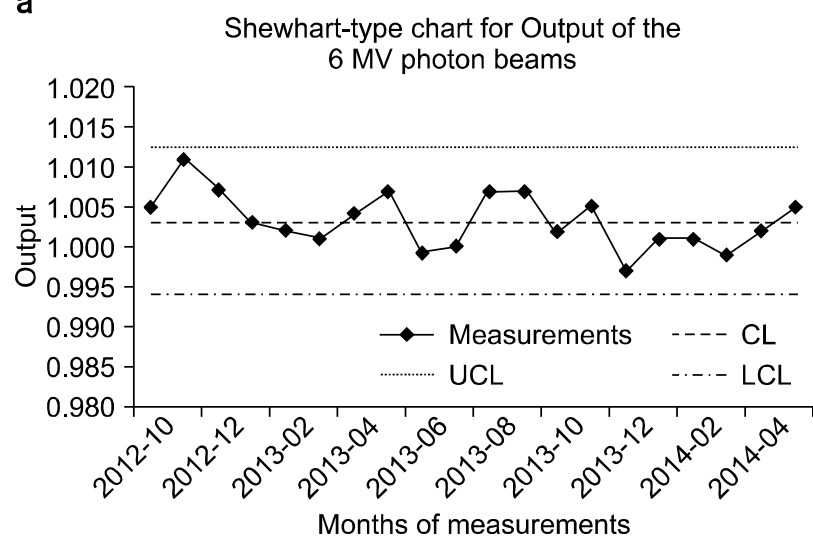

C

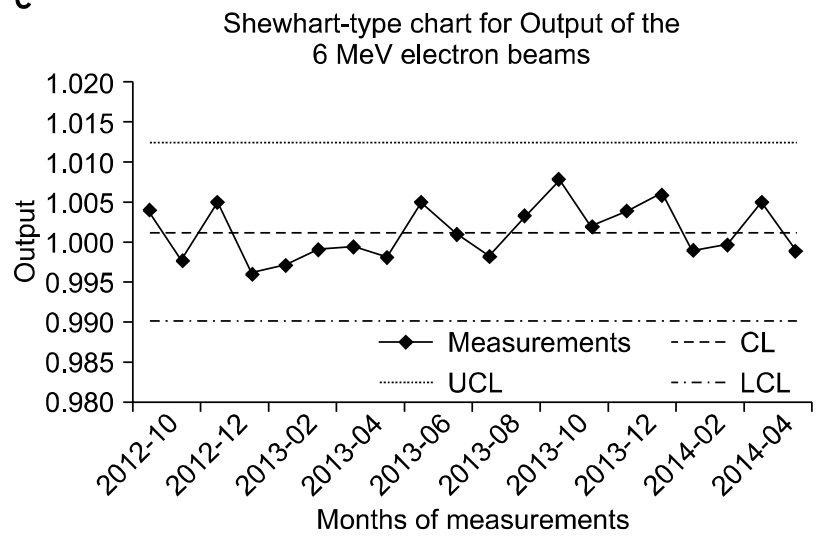

b

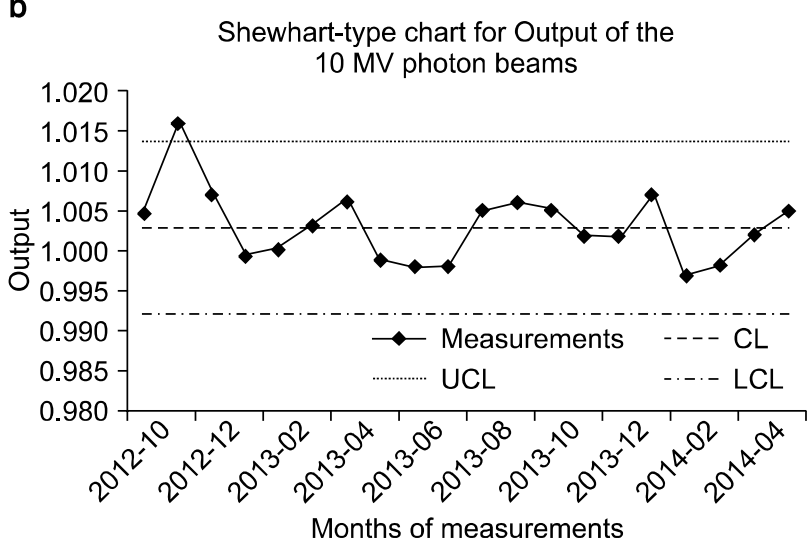

d

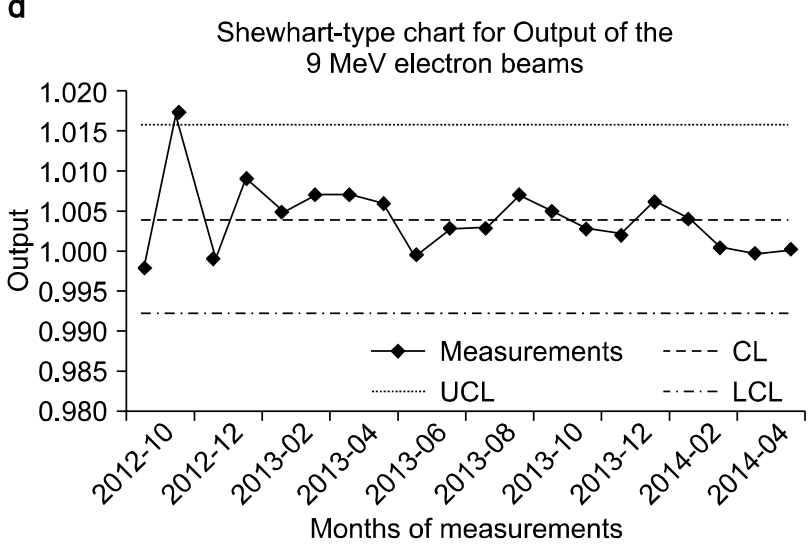

Fig. 1. Shewhart-type chart of the Output for the $6 \mathrm{MV}, 10 \mathrm{MV}$ photon beams and $6 \mathrm{MeV}, 9 \mathrm{MeV}$ electrons in the 21EX linear accelerator. (a) $6 \mathrm{MV}$ Photons, (b) $10 \mathrm{MV}$ Photons, (c) $6 \mathrm{MeV}$ electrons, and (d) $9 \mathrm{MeV}$ electrons.

Table 1. Upper control limit (UCL), Center line (CL), and Lower control limit (LCL) of the Shewhart-type chart for the 21EX, 21EX-S, and Novalis Tx linear accelerator.

\begin{tabular}{|c|c|c|c|c|c|c|c|c|}
\hline \multirow{2}{*}{ 21EX } & \multicolumn{2}{|c|}{ Photons } & \multicolumn{6}{|c|}{ Electrons } \\
\hline & $6 \mathrm{MV}$ & $10 \mathrm{MV}$ & $6 \mathrm{MeV}$ & $9 \mathrm{MeV}$ & & & $16 \mathrm{MeV}$ & $20 \mathrm{MeV}$ \\
\hline UCL & 1.012 & 1.014 & 1.013 & 1.016 & & & 1.020 & 1.015 \\
\hline CL & 1.003 & 1.003 & 1.001 & 1.004 & & & 1.004 & 1.003 \\
\hline LCL & 0.994 & 0.992 & 0.990 & 0.992 & & & 0.987 & 0.991 \\
\hline \multirow{2}{*}{ 21EX-S } & \multicolumn{2}{|c|}{ Photons } & \multicolumn{6}{|c|}{ Electrons } \\
\hline & $6 \mathrm{MV}$ & $10 \mathrm{MV}$ & $6 \mathrm{MeV}$ & $9 \mathrm{MeV}$ & & & $16 \mathrm{MeV}$ & $20 \mathrm{MeV}$ \\
\hline UCL & 1.013 & 1.014 & 1.015 & 1.009 & & & 1.013 & 1.015 \\
\hline CL & 1.003 & 1.004 & 1.003 & 1.003 & & & 1.006 & 1.005 \\
\hline LCL & 0.993 & 0.993 & 0.991 & 0.996 & & & 0.999 & 0.995 \\
\hline \multirow{2}{*}{ Novalis Tx } & \multicolumn{2}{|c|}{ Photons } & \multicolumn{6}{|c|}{ Electrons } \\
\hline & $6 \mathrm{MV}$ & $15 \mathrm{MV}$ & $4 \mathrm{MeV}$ & $6 \mathrm{MeV}$ & $9 \mathrm{MeV}$ & $12 \mathrm{MeV}$ & $16 \mathrm{MeV}$ & $20 \mathrm{MeV}$ \\
\hline UCL & 1.013 & 1.011 & 1.018 & 1.013 & 1.014 & 1.013 & 1.013 & 1.010 \\
\hline CL & 1.005 & 1.003 & 1.000 & 1.004 & 1.002 & 1.005 & 1.006 & 1.005 \\
\hline LCL & 0.997 & 0.995 & 0.981 & 0.996 & 0.990 & 0.998 & 0.999 & 1.000 \\
\hline
\end{tabular}


Se An Oh, et al : Analysis of Output Constancy Checks Using Process Control Techniques in Linear Accelerators

측정값을 찾아낼 때 적용된다.

EWMA chart는 측정 출력특성의 시간 변화에 대한 푸리 에 급수 전개에서 첫째항과 둘째항만을 선택하였다.

$$
E W M A_{t}=\lambda \cdot x_{t}+(1-\lambda) \cdot E W M A_{t-1}
$$

여기서 $\mathrm{t}=1,2,3$ 이고, $x_{t}$ 는 시간 $\mathrm{t}$ 에서의 측정값이다.

(1), (2), (3)식에 (4)식을 대입하여 계산하면 다음과 같은 식을 얻을 수 있다.

$$
\begin{aligned}
& U C L=\mu_{0}+L \cdot \sigma \sqrt{\frac{\lambda}{2-\lambda}\left[1-(1-\lambda)^{2 t}\right]} \\
& C L=\mu_{0} \\
& U C L=\mu_{0}-L \cdot \sigma \sqrt{\frac{\lambda}{2-\lambda}\left[1-(1-\lambda)^{2 t}\right]}
\end{aligned}
$$

a

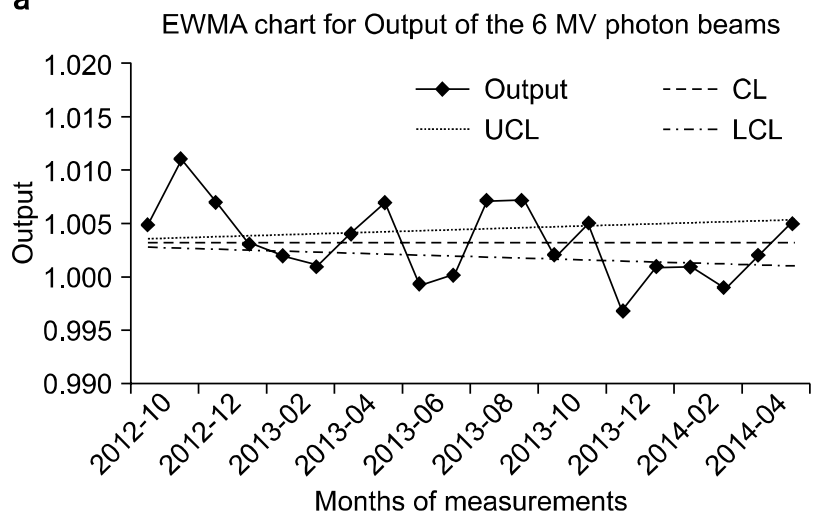

C

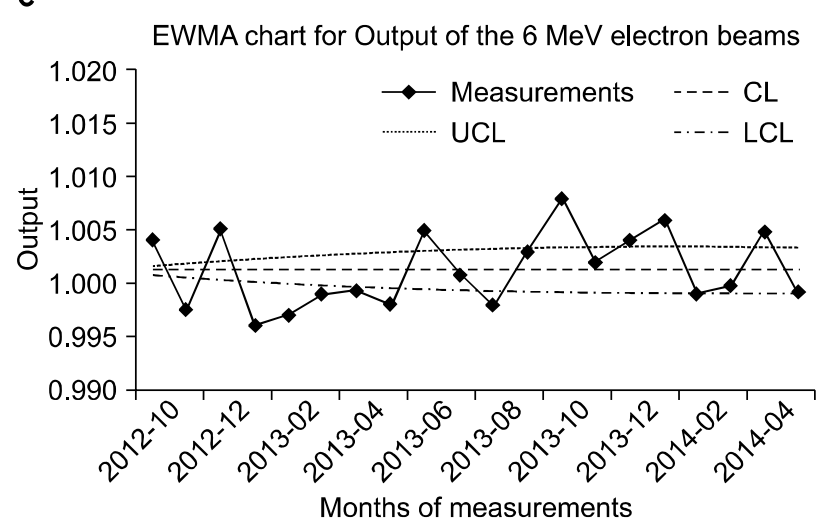

여기서 $\mu_{0}$ 는 평균값이며, shewhart-type control chart에서 $\bar{X}$ 와 같은 값이다. $\mathrm{t}$ 는 측정수이며, $\lambda$ 는 $0<\lambda \leq 1$ 의 값을 가지는 가중인자로 측정값의 변화가 점진적으로 이동이 있 을 때 EWMA Chart에 변화를 만든다.

$\mathrm{L}$ 은 측정값의 관리한계의 폭이다. $\lambda$ 와 $\mathrm{L}$ 은 여러 가지 값 을 가지는데 일반적으로 $\lambda$ 가 0.05 일 때 $\mathrm{L}$ 은 2.492 가 되며, $\lambda$ 가 0.10 일 때 $\mathrm{L}$ 은 2.703 이 되며, $\lambda$ 가 0.20 일 때 $\mathrm{L}$ 은 2.860 이 된다.

선형가속기 Varian Clinic $21 \mathrm{EX}$ 의 $6 \mathrm{MV}, 10 \mathrm{MV}, 6 \mathrm{MeV}$, $9 \mathrm{MeV}$ 에 대한 EWMA chart는 Fig. 2와 같다.

\section{Process capability and acceptability}

일반적으로 선형가속기의 출력 측정에서 실제 한계치는 $\pm 3 \%$ 이다. 이런 오차에 대한 한계치 값들은 $\mathrm{AAPM}$ 의 TG142 의 기준에 따라 작업을 수행하였다. 이 보고서의 오차 한계에 준하여 본 연구에서도 선형가속기의 출력을 측정하 였다.

b

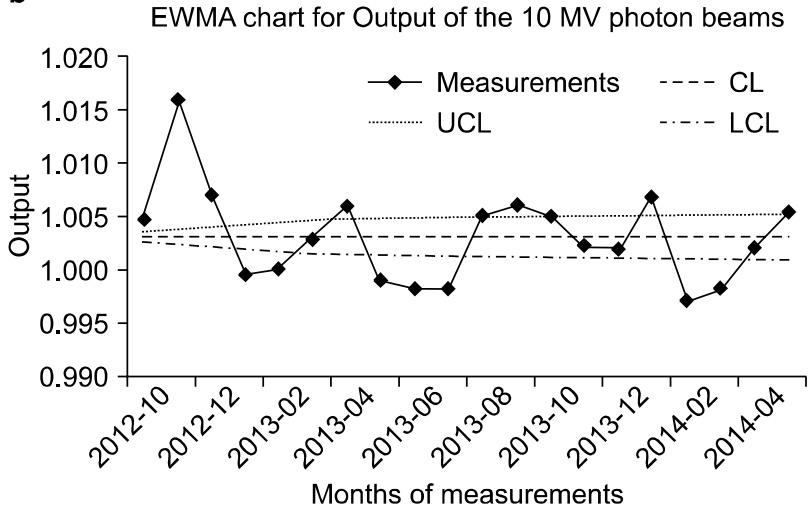

d

EWMA chart for Output of the $9 \mathrm{MeV}$ electron beams

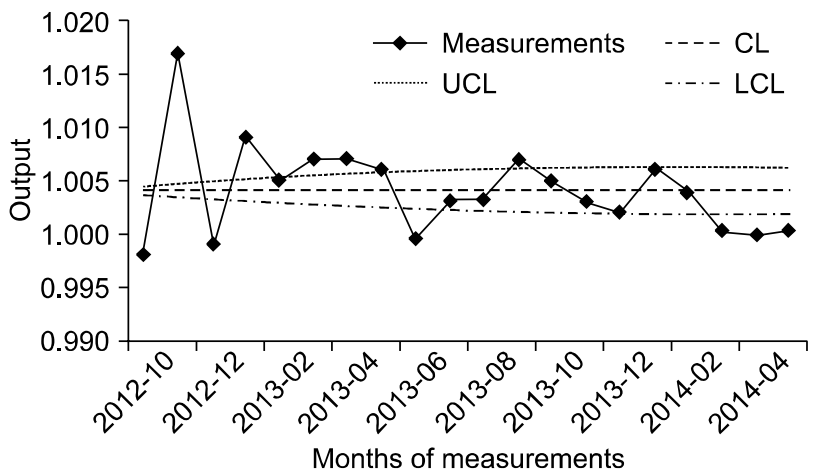

Fig. 2. Exponentially weighted moving average (EWMA) chart of the Output for the $6 \mathrm{MV}, 10 \mathrm{MV}$ photon beams and $6 \mathrm{MeV}, 9$ $\mathrm{MeV}$ electrons in the 21EX linear accelerator. (a) $6 \mathrm{MV}$ Photons, (b) $10 \mathrm{MV}$ Photons, (c) $6 \mathrm{MeV}$ electrons, and (d) $9 \mathrm{MeV}$ electrons. 
Table 2. Process capability $\left(C_{p}\right)$ and acceptability $\left(C_{p k}\right)$ of the output measurements for the 21EX, 21EX-S, and Novalis TX linear accelerator from September 2012 to April 2014.

\begin{tabular}{|c|c|c|c|c|c|c|c|c|}
\hline \multirow{2}{*}{$21 \mathrm{EX}$} & \multicolumn{2}{|c|}{ Photons } & \multicolumn{6}{|c|}{ Electrons } \\
\hline & $6 \mathrm{MV}$ & $10 \mathrm{MV}$ & $6 \mathrm{MeV}$ & $9 \mathrm{MeV}$ & & & $16 \mathrm{MeV}$ & $20 \mathrm{MeV}$ \\
\hline$C_{p}$ & 2.889 & 2.223 & 2.870 & 2.284 & & & 1.167 & 2.436 \\
\hline $\mathrm{C}_{\mathrm{pk}}$ & 2.574 & 1.999 & 2.748 & 1.976 & & & 1.417 & 2.185 \\
\hline \multirow{2}{*}{ 21EX-S } & \multicolumn{2}{|c|}{ Photons } & \multicolumn{6}{|c|}{ Electrons } \\
\hline & $6 \mathrm{MV}$ & $10 \mathrm{MV}$ & $6 \mathrm{MeV}$ & $9 \mathrm{MeV}$ & & & $16 \mathrm{MeV}$ & $20 \mathrm{MeV}$ \\
\hline$C_{p}$ & 1.919 & 1.614 & 1.946 & 2.281 & & & 2.098 & 1.765 \\
\hline $\mathrm{C}_{\mathrm{pk}}$ & 1.716 & 1.410 & 1.779 & 2.079 & & & 1.671 & 1.477 \\
\hline \multirow{2}{*}{$\begin{array}{c}\text { Novalis } \\
\text { Tx }\end{array}$} & \multicolumn{2}{|c|}{ Photons } & \multicolumn{6}{|c|}{ Electrons } \\
\hline & $6 \mathrm{MV}$ & $15 \mathrm{MV}$ & $4 \mathrm{MeV}$ & $6 \mathrm{MeV}$ & $9 \mathrm{MeV}$ & $12 \mathrm{MeV}$ & $16 \mathrm{MeV}$ & $20 \mathrm{MeV}$ \\
\hline$C_{p}$ & 2.996 & 2.296 & 1.995 & 2.292 & 2.458 & 2.718 & 3.986 & 4.420 \\
\hline $\mathrm{C}_{\mathrm{pk}}$ & 2.490 & 2.243 & 1.967 & 1.951 & 2.270 & 2.240 & 3.181 & 3.623 \\
\hline
\end{tabular}

이 과정에서 공정능력지수인 $\mathrm{C}_{\mathrm{p}}$ (Process capability) ${ }^{13)}$ 와 $\mathrm{C}_{\mathrm{pk}}$ (Process acceptability) ${ }^{13)}$ 를 이 연구에서 적용 하였다.

공정능력지수 $\mathrm{C}_{\mathrm{p}}$ 는 측정값의 상한치와 하한치의 집중도 를 나타내는 값이며, $\mathrm{C}_{\mathrm{pk}}$ 는 측정값의 중앙에서의 편차 정도 를 나타내는 값이다. 그러므로 측정기에 대한 매월 출력특 성에 대한 $\mathrm{C}_{\mathrm{p}}$ 은 매월 출력 특성을 $1 \mathrm{MU}$ 가 $1 \mathrm{~Gy}$ 가 되는데 얼마나 1 에 집중되어 있는가를 나타내는 값이며, 공정능력 $\mathrm{C}_{\mathrm{pk}}$ 는 매월 출력 특성을 $1 \mathrm{MU}$ 가 $1 \mathrm{~Gy}$ 가 되도록 결정하는 데 매월 가지는 편차의 정도를 나타내는 값이다.

공정능력지수 $\mathrm{C}_{\mathrm{p}}$ 는 상한치와 하한치의 차에 대한 표준 편차 나눔으로 구할 수 있다.

$$
C_{p}=\frac{U A L-L A L}{6 \cdot \sigma}
$$

여기서 UAL은 상한조치선(upper action limit)이며, LAL 은 하한조치선(lower action limit)이며, $\sigma$ 는 표준편차를 나 타내고 있다.

선형가속기 21 EX, 21 EX-S, Novalis Tx에 대한 output 측정값에 대한 $\mathrm{C}_{\mathrm{p}}$ 값은 Table 2와 Fig. 3 에 나타내었다.

$\mathrm{C}_{\mathrm{pk}}$ 는 출력특성을 측정하는 과정에서 충분히 특성화되어 사용되어져야 하는 지수이다. $\mathrm{C}_{\mathrm{pk}}$ 는 과정 중심이 가장 가까 운 한계에 얼마나 접근해 있는지를 나타내고 있는 값이다.

$$
C_{p k}=\min \left(\frac{U A L-\mu}{3 \cdot \sigma}, \frac{\mu-L A L}{3 \cdot \sigma}\right)
$$

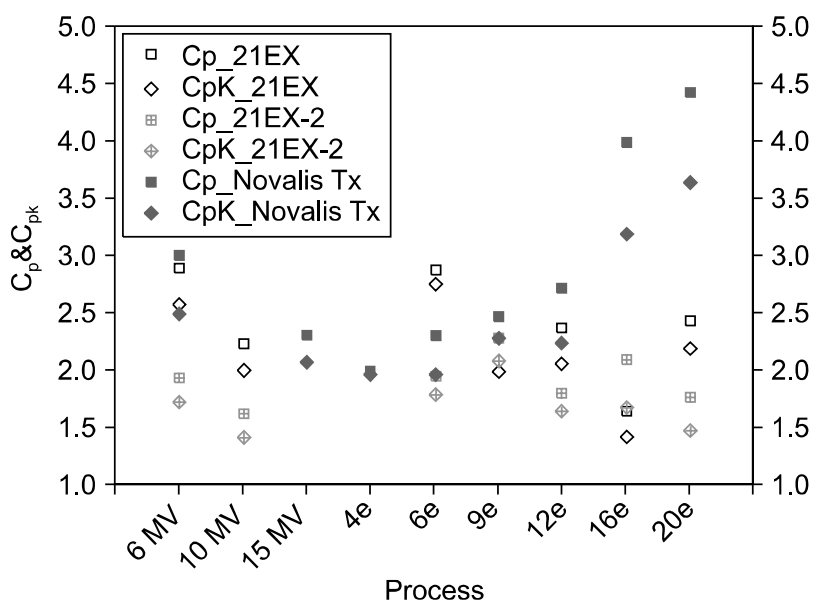

Fig. 3. Process capability $C_{p}$ and $C_{p k}$ for the process of 21EX, 21EX-S, and Novalis Tx.

선형가속기 $21 \mathrm{EX}, 21 \mathrm{EX}-\mathrm{S}$, Novalis Tx에 대한 $\mathrm{C}_{\mathrm{pk}}$ 에 대 한 값을 Table 2와 Figure 3에 $\mathrm{C}_{\mathrm{p}}$ 값과 같이 나타내었다.

\section{결 과}

본원에 설치되어 있는 Varian Clinic 21EX, 21EX-S와 Novalix Tx의 출력 특성을 측정한 에너지는 광자선 $6 \mathrm{MV}$, $10 \mathrm{MV}, 15 \mathrm{MV}$ 와 전자선 $4 \mathrm{MeV}, 6 \mathrm{MeV}, 9 \mathrm{MeV}, 12 \mathrm{MeV}$, $16 \mathrm{MeV}, 20 \mathrm{MeV}$ 였다. 이 데이터에 대한 Shewhart-Chart와 EWMA Chart를 표로 나타내었으며, $\mathrm{C}_{\mathrm{p}}$ 와 $\mathrm{C}_{\mathrm{pk}}$ 의 값을 계산 하였다. 
Se An Oh, et al : Analysis of Output Constancy Checks Using Process Control Techniques in Linear Accelerators

공정능력지수 $\mathrm{C}_{\mathrm{p}}$ 와 $\mathrm{C}_{\mathrm{pk}}$ 에 대해서 Varian Clinic $21 \mathrm{EX}$ 의 6 $\mathrm{MV}$ 에서 $\mathrm{C}_{\mathrm{p}}=2.889, \mathrm{C}_{\mathrm{pk}}=2.574$ 이며, $10 \mathrm{MV}$ 에서 $\mathrm{C}_{\mathrm{p}}=2.223$, $\mathrm{C}_{\mathrm{pk}}=1.999$ 이며, 전자선 $6 \mathrm{MeV}$ 에서 $\mathrm{C}_{\mathrm{p}}=2.870, \mathrm{C}_{\mathrm{pk}}=2.748$ 이 며, 전자선 $9 \mathrm{MeV}$ 에서 $\mathrm{C}_{\mathrm{p}}=2.284, \mathrm{C}_{\mathrm{pk}}=1.976$ 이며, 전자선 $12 \mathrm{MeV}$ 에서 $\mathrm{C}_{\mathrm{p}}=2.367, \mathrm{C}_{\mathrm{pk}}=2.051$ 이며, 전자선 $16 \mathrm{MeV}$ 에 서 $\mathrm{C}_{\mathrm{p}}=1.167, \mathrm{C}_{\mathrm{pk}}=1.417$ 이며, 전자선 $20 \mathrm{MeV}$ 에서 $\mathrm{C}_{\mathrm{p}}=$ $2.436, \mathrm{C}_{\mathrm{pk}}=2.185$ 였다. 출력특성은 $6 \mathrm{MV}$ 에서 집중도가 가 장 좋았으며, $16 \mathrm{MeV}$ 에서 집중도가 가장 떨어졌다.

공정능력지수 $\mathrm{C}_{\mathrm{p}}$ 와 $\mathrm{C}_{\mathrm{pk}}$ 에 대해서 Varian Clinic 21EX-S의 $6 \mathrm{MV}$ 에서 $\mathrm{C}_{\mathrm{p}}=1.919, \mathrm{C}_{\mathrm{pk}}=1.716$ 이며, $10 \mathrm{MV}$ 에서 $\mathrm{C}_{\mathrm{p}}=$ $1.614, \mathrm{C}_{\mathrm{pk}}=1.410$ 이며, 전자선 $6 \mathrm{MeV}$ 에서 $\mathrm{C}_{\mathrm{p}}=1.946, \mathrm{C}_{\mathrm{pk}}=$ 1.779 이며, 전자선 $9 \mathrm{MeV}$ 에서 $\mathrm{C}_{\mathrm{p}}=2.281, \mathrm{C}_{\mathrm{pk}}=2.079$ 이며, 전자선 $12 \mathrm{MeV}$ 에서 $\mathrm{C}_{\mathrm{p}}=1.799, \mathrm{C}_{\mathrm{pk}}=1.642$ 이며, 전자선 16 $\mathrm{MeV}$ 에서 $\mathrm{C}_{\mathrm{p}}=2.098, \mathrm{C}_{\mathrm{pk}}=1.671$ 이며, 전자선 $20 \mathrm{MeV}$ 에서 $\mathrm{C}_{\mathrm{p}}=1.765, \mathrm{C}_{\mathrm{pk}}=1.477$ 였다. 출력특성에서 $9 \mathrm{MeV}$ 의 집중도 가 가장 좋았으며, $10 \mathrm{MV}$ 의 집중도가 가장 떨어졌다.

공정능력지수 $\mathrm{C}_{\mathrm{p}}$ 와 $\mathrm{C}_{\mathrm{pk}}$ 에 대해서 Novalix $\mathrm{Tx}$ 의 $6 \mathrm{MV}$ 에 서 $\mathrm{C}_{\mathrm{p}}=2.996, \mathrm{C}_{\mathrm{pk}}=2.490$ 이며, $15 \mathrm{MV}$ 에서 $\mathrm{C}_{\mathrm{p}}=2.296, \mathrm{C}_{\mathrm{pk}}=$ 2.243 이며, 전자선 $4 \mathrm{MeV}$ 에서 $\mathrm{C}_{\mathrm{p}}=1.995, \mathrm{C}_{\mathrm{pk}}=1.967$ 이며, 전자선 $6 \mathrm{MeV}$ 에서 $\mathrm{C}_{\mathrm{p}}=2.292, \mathrm{C}_{\mathrm{pk}}=1.951$ 이며, 전자선 9 $\mathrm{MeV}$ 에서 $\mathrm{C}_{\mathrm{p}}=2.458, \mathrm{C}_{\mathrm{pk}}=2.270$ 이며, 전자선 $12 \mathrm{MeV}$ 에서 $\mathrm{C}_{\mathrm{p}}=2.718, \mathrm{C}_{\mathrm{pk}}=2.240$ 이며, 전자선 $16 \mathrm{MeV}$ 에서 $\mathrm{C}_{\mathrm{p}}=3.986$, $\mathrm{C}_{\mathrm{pk}}=3.181$ 이며, 전자선 $20 \mathrm{MeV}$ 에서 $\mathrm{C}_{\mathrm{p}}=4.420, \mathrm{C}_{\mathrm{pk}}=3.623$ 였다. 출력 특성에서 $20 \mathrm{MeV}$ 에서 4.420 를 나타내어 집중도 가 가장 좋았으며, $4 \mathrm{MeV}$ 의 집중도가 가장 떨어졌다. 에너 지에 따른 측정편차는 $\mathrm{C}_{\mathrm{p}}$ 와 $\mathrm{C}_{\mathrm{pk}}$ 의 크기와 차이를 보면 모 든 에너지에서 거의 비슷하지만 다른 치료기들에 비하여 조금 크게 나타났다.

Varian Clinic 21EX의 Shewhart-type chart를 예로 보면, 10 $\mathrm{MV}$ 에서 1.012 로 하나의 측정값이 UCL을 벗어났으며, 전 자선 $9 \mathrm{MeV}$ 에서 1.017 로 하나의 측정값이 $\mathrm{UCL}$ 을 벗어났 으며, 전자선 $12 \mathrm{MeV}$ 에서 1.016 로 하나의 측정값이 $\mathrm{UCL}$ 을 벗어났으며, 그 외의 모든 측정값은 한계치 범위 안에 분포 하고 있었다. 본원의 Varian Clinic 21EX 선형가속기의 모 든 에너지에서의 output 측정값의 계산된 $\mathrm{C}_{\mathrm{p}}$ 와 $\mathrm{C}_{\mathrm{pk}}$ 의 값을 보면, 2.0 근처의 값으로 매우 안정적이고 정확한 출력특성 을 나타내고 있었다.

각각의 장비에 따른 평균 $\mathrm{C}_{\mathrm{p}}$ 와 $\mathrm{C}_{\mathrm{pk}}$ 의 값을 보면, $21 \mathrm{EX}$ 가 2.384와 2.136, 21EX-S가 1.917과 1.682, Novalis Tx가 2.895 와 2.473으로 Novalis Tx가 가장 안정적이고 정확한 출력특 성을 나타내고 있었다.

\section{고찰 및 결론}

Sanghangthum 등 ${ }^{5}$ 은 선형가속기의 출력특성을 shewhart type chart와 EWMA chart를 가지고 분석하였다. 이들은 프 로세스의 작은 움직임을 파악하기 위해서 EWMA 방식이 유용하다고 언급하였다. 또한, weighting factor $(\lambda)$ 와 측정 값의 관리한계의 폭 $(\mathrm{L})$ 을 $\lambda=0.1, \mathrm{~L}=2.703$ 을 사용하기를 권고하여, 본 연구에서는 Sanghangthum 등이 제안한 $\lambda$ 와 $\mathrm{L}$ 값을 사용하였다. 위에서 제시한 값보다 큰 $\lambda$ 와 $\mathrm{L}$ 을 사용 하게 된다면, Sanghangthum에서 보여준바와 같이 보다 큰 한계의 폭을 볼 수 있을 것이다. 측정된 출력의 값이 이보 다 큰 경우에는 $\lambda=0.05, \mathrm{~L}=2.492$ 값을 사용하여 프로세스 의 작은 움직임을 빠르게 확인 할 수 있을 것이다. 또한, Sanghangthum 등 ${ }^{5}$ 은 선형가속기의 출력특성을 IAEA의 TRS-398의 가이드라인에 따라 RBA-3을 사용하여 매일 출 력특성을 확인하여 통계분석을 시도하였는데, 전자선 12 $\mathrm{MeV}$ 와 전자선 $20 \mathrm{MeV}$ 를 제외하고는 $\mathrm{C}_{\mathrm{p}}$ 와 $\mathrm{C}_{\mathrm{pk}}$ 값이 2.0 정 도를 나타내고 있었다.

Shewhart-type control chart는 attribute control chart와 variable control chart로 구분할 수 있는데, 본 연구의 출력선량 측정과 같이 측정값이 연속적인 때는 variable control chart 로 볼 수 있을 것이다. 본 연구에서, Shewhart-type control chart를 정의 하면서 식 (1)과 식 (3)의 $\mathrm{d}_{2}$ 는 소그룹의 크기 에 의존하는 상수로 설명하였으며, 본 연구에서는 각각의 출력선량의 측정은 한 개의 소그룹으로 볼 수 있기 때문에, individual $(\mathrm{X})$ chart로 사용되었다. 또한, 여러 소그룹이 사 용되었을 때는 Pawlicki 등 ${ }^{8}$ 의 논문을 참고 하여 소그룹 (n) 에 따른 정확도 상수 $\left(\mathrm{d}_{2}\right)$ 를 사용할 수 있다.

Klein 등 ${ }^{12}$ 은 선형가속기의 출력특성은 임상적으로 의미 가 있는 적절한 실제 한계치를 가져야 하며, 특정지점의 측 정값뿐만 아니라 시간에 따라 일정한 값을 가지는 것도 임 상적으로 의미가 있다고 보고하였다.

Grattan과 Hounsel1 ${ }^{13)}$ 은 선형가속기의 출력 특성을 통계 학적으로 분석하는데 이온전리함을 사용하였는데 전자선 $9 \mathrm{MeV}$ 와 $16 \mathrm{MeV}$ 에서 안정적이지 못했음을 보고하였다.

Reynolds와 Stoumbos ${ }^{14)}$ 는 어떤 경우에서는, 측정 과정에 서 큰 변화가 있거나 또는 작은 움직임을 측정하기 위한 Shewahart-type Chart 없이 EWMA Chart가 target으로부터 표준편차의 값이 주어진다면 EWMA의 적용이 가능하다고 보고하였다.

결론적으로, 본원 치료기(21EX, 21EX-S, Novalis Tx)를 
2012년 9월부터 2014년 4월까지 출력특성에 대한 통계적 분석인 Shewhart-type Chart와 EWMA Chart, 공정능력지수 $\mathrm{C}_{\mathrm{p}}$ 와 $\mathrm{C}_{\mathrm{pk}}$ 의 값의 분석을 통하여 살펴보았다. Shewhart-type Chart를 통하여 출력선량의 측정값의 큰 변화점을 찾을 수 있었고, EWMA Chart를 통하여 출력선량의 측정값의 미세 한 변화점을 알아 볼 수 있었다. 본원의 치료기의 공정능력 지수 $\mathrm{C}_{\mathrm{p}}$ 와 $\mathrm{C}_{\mathrm{pk}}$ 를 통하여 $21 \mathrm{EX}$ 가 2.384 와 $2.136,21 \mathrm{EX}-\mathrm{S}$ 가 1.917 과 1.682, Novalis Tx가 2.895와 2.473으로 Novalis Tx가 가장 안정적이고 정확한 출력특성을 나타내고 있었다.

\section{References}

1. Oh SA, Kang MK, Kim SK, Yea JW: Comparison of IMRT and VMAT Techniques in Spine Stereotactic Radiosurgery with International Spine Radiosurgery Consortium Consensus Guidelines. Prog. Med. Phys. 24(3):145-153 (2013)

2. Andreo P, Burns D T, Hohlfeld K, et al: Absorbed dose determination in external beam radiotherapy: An international Code of Practice for dosimetry based on standards of absorbed dose to water IAEA Technical Report Series No 398 IAEA, Vienna (2000)

3. Boyer A, Biggs P, Galvin J, et al: Basic applications of multileaf collimators. Report of the AAPM Radiation Therapy Committee Task Group No. 50. Med Phys (2001)

4. ICRU Report 83: Prescribing, recording and reporting photon-beam intensity-modulated radiation therapy (IMRT). International Commission on Radiation Units and Measurements, 10:1$106(2010)$
5. Sanghangthum T, Suriyapee S, Srisatit S, Pawlicki T: Retrospective analysis of linear accelerator output constancy checks using process control techniques. J Appl Clin Med Phys 14(1):147-60 92013)

6. Ekaette E, Lee RC, Cooke DL, Iftody S, Craighead P: Probabilistic fault tree analysis of a radiation treatment system. Risk Analysis 27(6):1395-410 (2007)

7. Huq MS, Fraass BA, Dunscombe PB, et al: A method for evaluating quality assurance needs in radiation therapy. Int $J$ Radiat Oncol Biol Phys 71(1 Suppl):S170-S173 (2008)

8. Pawlicki T, Whitaker M, Boyer A: Statistical process control for radiotherapy quality assurance. Med Phys 32(9):2777-86 (2005)

9. Tennant R, Mohammed MA, Coleman JJ, Martin U: Monitoring patients using control charts: a systematic review. Int J Qual Health Care 19(4):187-94 (2007)

10. Nordstrom F, Wetterstedt S, Johnsson S, Ceberg C, Back SAJ: Control chart analysis of data from a multicenter monitor unit verification study. Radiother Oncol 102(3):364.70 (2012)

11. Carey RG and Lloyd RC: Measuring quality improvement in healthcare: a guide to statistical process control application. Wisconsin, WI: Quality Press (2001)

12. Klein EE, Hanley J, Bayouth J, et al: Task Group 142 report: quality assurance of medical accelerators. Med Phys 36(9):4197-212 (2009)

13. Grattan MW and Hounsell AR: Analysis of output trends from Varian 2100C/D and 600C/D accelerators. Phys Med Biol 56(1):N11-N19 (2011)

14. Reynolds MR and Stoumbos ZG: Should exponentially weighted moving average and cumulative sum charts be used with Shewhart limits Technometrics 47(4):409-24 (2005) 


\section{선형가속기의 출력 특성에 대한 공정능력과 공정가능성을 이용한 통계적 분석}

*영남대학교 의료원 방사선종양학과, ${ }^{\dagger}$ 영남대학교 의과대학 방사선종양학교실,

${ }^{\ddagger}$ 이화여자대학교 의과대학 이대목동병원 방사선종양학교실

$$
\text { 오세안* } \cdot \text { 예지원 }{ }^{\dagger} \cdot \text { 김상원* } \cdot \text { 이레나 }{ }^{\ddagger} \cdot \text { 김성규* }{ }^{\dagger}
$$

이 연구의 목적은 본원이 보유하고 있는 선형가속기들의 출력 특성을 Shewhart-type Chart, EWMA Chart, 공정능력지수 $\mathrm{C}_{\mathrm{p}}$ 와 $\mathrm{C}_{\mathrm{pk}}$ 을 이용한 통계적 분석으로 품질보증에 대한 결과를 평가하고자 한다. 측정값은 의학물리사에 의하여 2012년 9 월부터 2014년 4월까지 매월 측정된 각각 치료기들(21EX, 21EX-S, Novalis TX)의 출력측정값을 사용하였다. 치료기들의 출력 특성은 IAEA TRS-398의 가이드라인을 따랐으며, 측정 에너지는 광자선 $6 \mathrm{MV}, 10 \mathrm{MV}, 15 \mathrm{MV}$ 와 전자선 $4 \mathrm{MeV}, 6$ $\mathrm{MeV}, 9 \mathrm{MeV}, 12 \mathrm{MeV}, 16 \mathrm{MeV}, 20 \mathrm{MeV}$ 였다. 매월 측정하여 교정한 출력특성에 대한 통계학적 분석이며, 가중인자와 측 정값의 관리한계의 폭은 $\lambda=0.10, \mathrm{~L}=2.703$ 로 계산되었으며, 공정능력 $\mathrm{C}_{\mathrm{p}}$ 와 $\mathrm{C}_{\mathrm{pk}}$ 는 모든 선형가속기(21EX, 21EX-S, Novalis TX)의 모든 에너지에서 1이상이었다. Shewhart-type Chart를 통하여 출력선량의 측정값의 큰 변화점을 찾을 수 있었고, EWMA Chart를 통하여 출력선량의 측정값의 미세한 변화점을 알아 볼 수 있었다. 본원의 치료기의 공정능력지 수 $\mathrm{C}_{\mathrm{p}}$ 와 $\mathrm{C}_{\mathrm{pk}}$ 를 통하여 21EX가 2.384와 2.136, 21EX-S가 1.917과 1.682, Novalis TX가 2.895와 2.473으로 Novalis TX가 가장 안정적이고 정확한 출력특성을 나타내고 있었다.

중심단어: 출력선량, 선형가속기, 품질보증, 공정능력, 공정가능성 